\title{
The Prevalence of Self Medication and the Factors influencing its Practice in Pharmacy Students of Karachi, Pakistan: A mix mode study
}

\author{
Atta Abbas Naqvi', Rizwan Ahmad², Omar Qadeer ${ }^{3}$, Muhammad Hassan Khan ${ }^{3}$, Muhammad Nehal Nadir ${ }^{3}$, Madiha Alim $^{3}$ \\ 'Department of Pharmacy Practice, College of Clinical Pharmacy, University of Dammam, Dammam 31441, KINGDOM OF SAUDI ARABIA. \\ ${ }^{2}$ Natural Products and Alternative Medicines, College of Clinical Pharmacy, University of Dammam, Dammam 31441, KINGDOM OF SAUDI ARABIA. \\ ${ }^{3}$ Faculty of Pharmacy, Ziauddin University, Clifton, Karachi 75600, PAKISTAN.
}

\begin{abstract}
Objective: The study investigated the opinions and beliefs of the pharmacy students towards self medication and highlighted factors which have the potential to indulge them in such practice. Methods: A mix mode cross sectional study was conducted in different pharmacy teaching institutes of Karachi, Pakistan for 2 months. All pharmacy students were included. They were handed a questionnaire related to self medication. Also, they were asked to appear in interviews. The data was analyzed by SPSS $\vee 20$. The study was ethically approved. Result: Majority of the students ( $N=221,94 \%)$ were between $18-23$ years and majority were females $(N=198,84.3)$. Prevalence of self medication was reported at $67.2 \%(60.8 \%-73.2 \%$ for $95 \% \mathrm{Cl})$. Mild problems $(\mathrm{N}=54,34.2 \%)$ and previous experience $(\mathrm{N}=17,10.8 \%)$ were major reasons in favor of indulging in self medication while importance of physician consultation ( $N=30,39 \%)$ and fear of adverse drug reactions $(N=12$, $15.5 \%)$ were major reasons against indulgence in self medication. Statistical association was significant between number of siblings and tendency to indulge in self medication $(P$ value $<0.05)$. Conclusion: The economic barriers and familial competition has the potential to prompt an individual to indulge in self medication which is further facilitated by knowledge of pharmacy and ease of availability of prescription drugs.
\end{abstract}

Key words: Prevalence, Self medication, Students, Mix mode, Karachi, Pakistan.

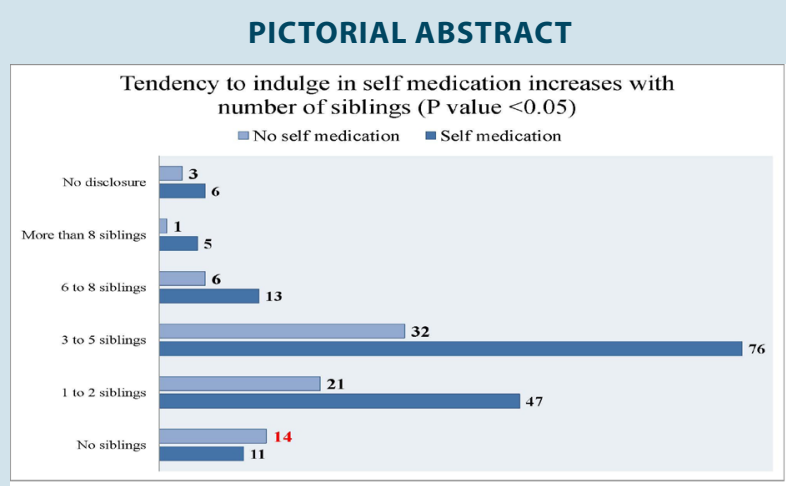

Prevalence of self medication among pharmacy students was $67.2(60.8 \%-73.2 \%$ for $95 \% \mathrm{CI})$

Correspondence :

Atta Abbas Naqvi,

Department of Pharmacy Practice, College of Clinical Pharmacy, University of Dammam, Dammam 31441, KINGDOM OF SAUDI ARABIA.

E-mail: bg33bd@student.sunderland.ac.uk; atta_abbas@hotmail.com

DOI: 10.5530/jyp.2016.3.11

\section{INTRODUCTION}

Self medication is the use of non prescription and prescription medicines by one's own initiative to treat self recognized symptoms and conditions. This practice is debatable in health care circles as it can be harmful to the individual. ${ }^{1}$ The ease of access of over the counter OTC medications and to some extent non OTC medicines (in non regulated pharmaceutical retailing) has contributed majorly to this type of self care. ${ }^{2}$

Self medication has a broad impact and has its roots from two major contributors, i.e. economic reluctance and the sociocultural behavior of the population. The ease of access of medication at home is a major contributor to the issue of self medication. Sometimes getting a proper regimental therapy is not deemed important as the medicines at home are easily accessible and symptomatic treatment is usually preferred. Economic reluctance is the limited availability of resources distributed among the beneficiaries which ultimately results in either conservation of resource or minimum utilization. This principle can be adopted in self medication as the family members having limited economic support find self medication more appropriate rather undergoing costly consultations. $^{3}$

The health care system of Pakistan is still in process of equipping modern medical facilities and improving the overall health infrastructure. ${ }^{4,5}$ The availability of non OTC medicines in retail pharmacies without any prescription or reutilizing an old prescription contributes to dysregulated pharmacy practices and further allows patients to indulge in self medica- tion. ${ }^{1,6}$ The non regulated availability of prescription medicines is also a major contributor to the problem. ${ }^{7}$ The pharmaceutical retailers tend to indulge in the sale of the prescription medications without a valid prescription. ${ }^{8}$ This activity is also observed and this ease of availability provides the means for indulging in self medication as well. ${ }^{9}$ In addition, the OTC medicines such as analgesics, anti tussives, etc. though normally considered as risk free, but their excessive use can cause serious adverse reactions which adds to the ill health and further contributes towards the potential to indulge in self medication. ${ }^{10}$ The extent to which it is harmful remains debatable. ${ }^{12}$

The malpractice of the pharmaceutical drug retailers at the level of communities exploits the self medication potential of the patients especially in developing countries. It might be due to a number of reasons such as the socioeconomic status of the patients, health care dynamics of the country, patient mindset, ease of availability of prescription medication and experience of drug retailers as a substitute for prescriber. ${ }^{6}$ Appropriate self medication requires the individual to accurately recognize symptoms, set therapeutic objectives, select the appropriate medicine to be used for his medical condition, determine the appropriate dose and schedule by taking into account the medical history, contra indications, and possible adverse effects of the medicine. ${ }^{11}$

Referring to Pakistan's health care dynamics, it is quite similar to developing countries. The malpractice in the health sector and pharmaceutical drug 
retailing render medications to be freely available in unlimited quantities without the need of a prescription. The limited number of pharmacists employed in pharmacy drug stores leads to unchecked prescription filling which pose a health hazard to the patients. ${ }^{6}$

Various studies have been carried out on the subject in Pakistan in different medical universities and reported self medication prevailing amongst students however no study at present emphasizes on the self medication among pharmacy students in a detailed qualitative manner. The pharmacy institutions provide basic knowledge and awareness regarding ethical use that includes the knowledge of the medicines and consequences for abuse. ${ }^{13}$ Thus, the rationale of the study was to find out if the pharmacy students, having core knowledge about self medication, indulge in the practice or refrain from it. The study investigated the opinions and beliefs of the pharmacy students that led to their decision making in favor or against indulging in self medication.

\section{MATERIALS AND METHODS}

A mix mode cross sectional study was designed with the aim of documenting self medication practice among the students of pharmacy education in different institutes of Karachi, Pakistan.

\section{Duration of the study}

The duration of the study was of two months, i.e. form October 2014 till November 2014.

\section{Inclusion and exclusion criteria}

The inclusion and exclusion criteria were set as all students of pharmacy education were included and all others were excluded. Moreover, those who did not consent to participate and incomplete questionnaires were also excluded from the study.

\section{Venue of the study}

The venue of the study was the pharmacy teaching institutes of Karachi, Pakistan. Karachi is the largest city of Pakistan and a superior economic zone. Its population is around 23.5 million and is the most developed city in terms of infrastructure. ${ }^{14}$ There are 17 public sector and 17 private sector pharmacy institutions currently registered in Pakistan with a total yearly intake of 2645 pharmacy undergraduates approved by the Pharmacy Council of Pakistan. ${ }^{15}$ Out of these, 7 pharmacy teaching universities i.e. 3 public sector and 4 private sector are based in the city of Karachi with total approved yearly intake of 1160 undergraduate pharmacy students which accounts for $43.8 \%$ of total yearly intake of the country. These 7 pharmacy institutes of Karachi were approached for data collection. The study commenced after getting approval from the institutes.

\section{Enrollment and sampling procedure}

Convenient sampling was employed in the study. A total of 7 pharmacy institutes of Karachi, Pakistan were requested to allow the study to be carried out in their pharmacy faculties of which 3 pharmacy institutes granted permission. The pharmacy students of those institutes were approached in their off-peak hours (free time) by the volunteers for gathering data. The students were explained the study purpose and objectives. A total of 294 students were approached and after consent, 250 students were available. After passing through inclusion/exclusion criteria, 235 responses were received giving a response rate of $94 \%$. A detailed procedure of student enrollment is described in Figure 1.

\section{Research instrument}

The research instrument consisted of data questionnaire containing open ended and close ended questions in English language followed by a small interview.

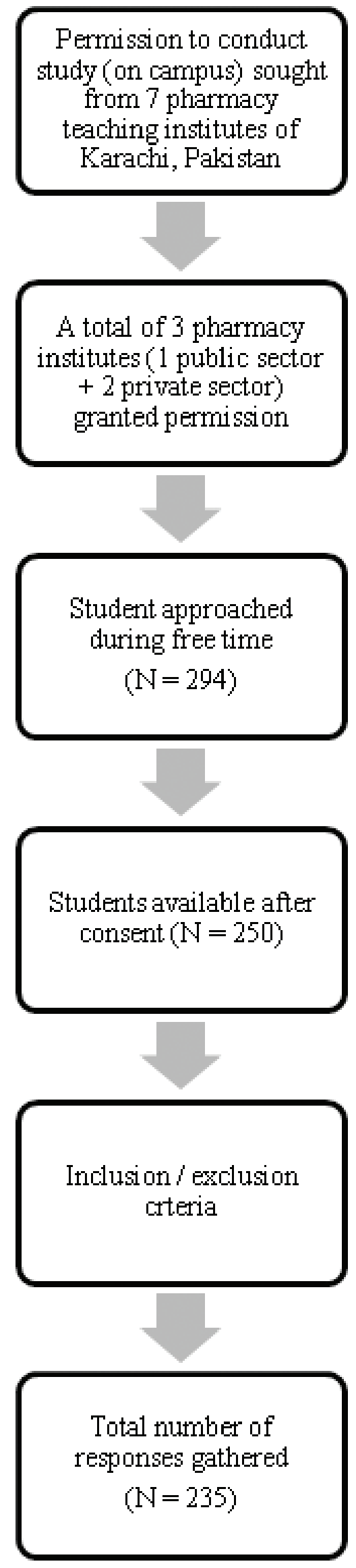

Figure 1: Flowchart of student enrollment. 


\section{Piloting and validation of the research instrument}

The quantitative aspect of the study i.e. research instrument was piloted on 23 pharmacy students and validated by a team consisting of a university professor, 2 health care professionals and 1 clinical pharmacist. It took just under than $5 \mathrm{~min}$ to fill in the response in the questionnaire. After piloting and analyzing the pilot results, the questionnaire was modified and some variables were fortified with more options. The questionnaire was again piloted by the experts on 9 students and validated. Qualitative findings adhered to COREQ guidelines, thematic analysis was conducted and triangulation was also applied to the qualitative aspect of the study for validating the findings. A flowchart of questionnaire modifications is described in Figure 2.

\section{Statement of consent}

The students were explained the objectives of the study and their consent were obtained before the data collection.

\section{Data analysis}

The data thus gathered was analyzed by SPSSv20 (Statistical Package for Social Sciences version 20) and the demographic results were explained in sample (N) and percentages (\%). Cross tabulation and Chi square $X 2$ test was also employed. Statistical significance was accepted at $\mathrm{P}$ values less than 0.05 . The prevalence was calculated by MedCalc ${ }^{\circ}$.

\section{Ethical approval}

The study was ethically approved by the Research Review Committee of Clifton Hospital, Karachi, Pakistan. (Ethical Approval Letter \# 114-02-14).

\section{Conceptual framework}

A two tailed hypothesis was formulated i.e. self medication in pharmacy students is high and familial competition is a contributing factor for indulgence in self medication.

\section{RESULTS}

Out of a total of $\mathrm{N}=250$ students, 235 responses were received giving a response rate of $94 \%$. The results are expressed in demographic and self medication information.

\section{Demographic information}

The study incorporated the pharmacy students from different age groups. Majority of the students $(\mathrm{N}=221,94 \%)$ were in the age group of 18-23 years followed by a small segment $(\mathrm{N}=13,5.5 \%)$ in age group of 24-30 years and very few $(\mathrm{N}=1,0.5 \%)$ above 30 years. In terms of gender, majority of the respondents were the females $(\mathrm{N}=198,84.3)$ followed by males $(\mathrm{N}=37,15.7 \%)$. Furthermore, the bulk of the students $(\mathrm{N}=72$, $30.6 \%$ ) lived in the district Central of Karachi city followed by those living in district East $(\mathrm{N}=45,19.2 \%)$ while some students $(\mathrm{N}=39,16.6 \%)$ were living in district South and few in district Malir $(\mathrm{N}=30,12.8 \%)$. A small segment $(\mathrm{N}=9,3.8 \%)$ lived in district West and some students $(\mathrm{N}=40,17 \%)$ were reluctant to give this information. Additionally, almost half of the target segment $(\mathrm{N}=108,46 \%)$ had 3-5 siblings followed by those $(\mathrm{N}=68,28.9 \%)$ who had $1-2$ siblings and some $(\mathrm{N}=19,8.1 \%)$ with 6-8 siblings. Few $(\mathrm{N}=6,2.6 \%)$ had more than 8 siblings and some $(\mathrm{N}=25,10.6 \%)$ had none. However, a small proportion of the target population $(\mathrm{N}=9,3.8 \%)$ did not disclose their information in this regard. Majority of the students $(\mathrm{N}=226,96.2 \%)$ appeared to be single when information about marital status was sought. Some were married $(\mathrm{N}=7,3 \%)$ while few $(\mathrm{N}=2,0.8 \%)$ did not reveal this information. The results of the demographic information in tabulated in Table 1.

Amongst them, an overwhelming majority of the students $(\mathrm{N}=224$, 95.3\%) were pharmacy undergraduates while some $(\mathrm{N}=9,3.8 \%)$ were graduates followed by very few post graduates $(\mathrm{N}=2,0.9 \%)$. By break down of professional years of undergraduate pharmacy education, bulk

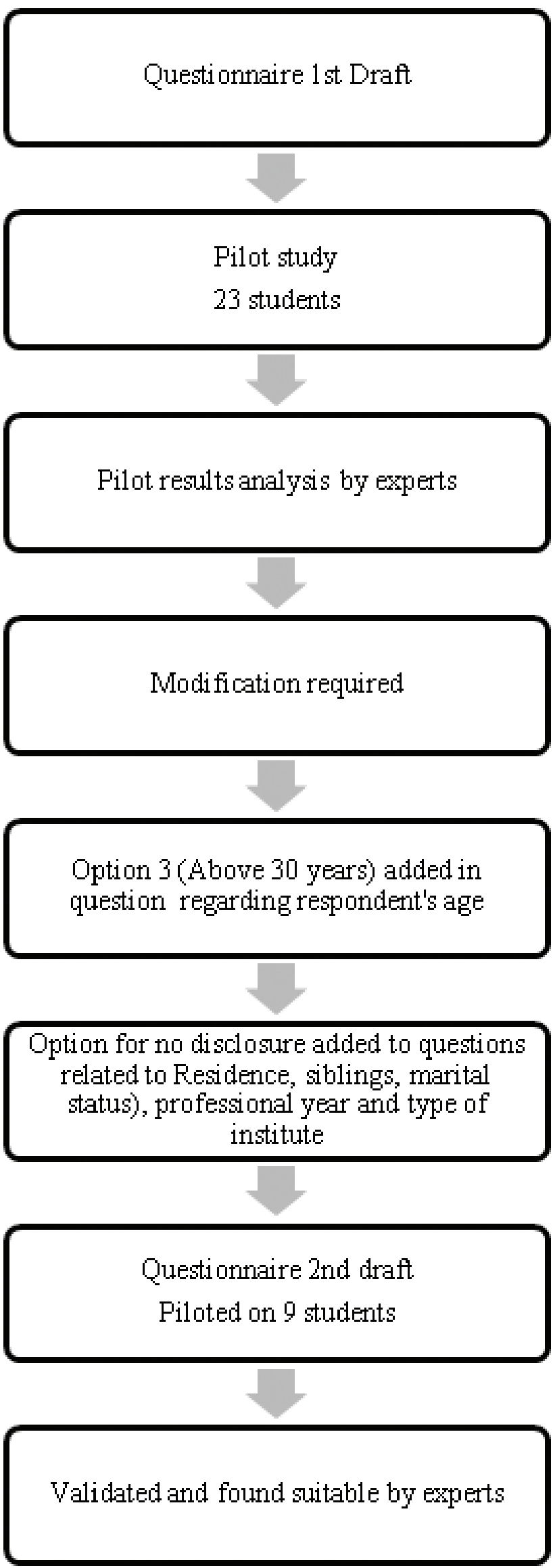

Figure 2: Flowchart of piloting and validation of questionnaire. 
Table 1: Summary of demographic information

\begin{tabular}{|c|c|c|c|c|}
\hline S.No & Demographic information & Sample (N) & Percentage (\%) & $P$ value \\
\hline 1 & Age & & & $<0.01$ \\
\hline 1.1 & Between $18-23$ years & 221 & 94 & \\
\hline 1.2 & Between 24-30 years & 13 & 5.5 & \\
\hline 1.3 & Above 30 years & 1 & 0.5 & \\
\hline 1.4 & Total & 235 & 100 & \\
\hline 2 & Gender & & & $<0.01$ \\
\hline 2.1 & Male & 37 & 15.7 & \\
\hline 2.2 & Female & 198 & 84.3 & \\
\hline 2.3 & Total & 235 & 100 & \\
\hline 3 & Residence & & & $<0.01$ \\
\hline 3.1 & Did not disclose & 40 & 17 & \\
\hline 3.2 & District South & 39 & 16.6 & \\
\hline 3.3 & District East & 45 & 19.2 & \\
\hline 3.3 & District West & 9 & 3.8 & \\
\hline 3.4 & District Central & 72 & 30.6 & \\
\hline 3.5 & District Malir & 30 & 12.8 & \\
\hline 3.7 & Total & 235 & 100 & \\
\hline 4 & Siblings & & & $<0.01$ \\
\hline 4.1 & Did not disclose & 9 & 3.8 & \\
\hline 4.2 & None & 25 & 10.6 & \\
\hline 4.3 & Between 1-2 siblings & 68 & 28.9 & \\
\hline 4.4 & Between 3-5 siblings & 108 & 46 & \\
\hline 4.5 & Between 6-8 siblings & 19 & 8.1 & \\
\hline 4.6 & More than 8 siblings & 6 & 2.6 & \\
\hline 4.7 & Total & 235 & 100 & \\
\hline 5 & Marital Status & & & $<0.01$ \\
\hline 5.1 & Did not disclose & 2 & 0.8 & \\
\hline 5.2 & Single & 226 & 96.2 & \\
\hline 5.3 & Married & 7 & 3 & \\
\hline 5.4 & Total & 235 & 100 & \\
\hline
\end{tabular}

Table 2: Summary of educational information

\begin{tabular}{ccccc}
\hline S.No & Educational Information & Sample (N) & Percentage (\%) & P value \\
\hline $\mathbf{1}$ & Education & & & $<0.01$ \\
1.1 & Undergraduate & 224 & 95.3 & \\
1.2 & Graduate & 9 & 3.8 & \\
1.3 & Post Graduate & 2 & 0.9 & \\
$\mathbf{1 . 4}$ & Total & $\mathbf{2 3 5}$ & $\mathbf{1 0 0}$ & \\
$\mathbf{2}$ & Professional Year & & & $<0.05$ \\
2.1 & Not disclosed & 38 & 16.9 & \\
2.2 & $1^{\text {st }}$ Professional & 56 & 25 & \\
2.3 & $2^{\text {nd }}$ Professional & 35 & 15.6 & \\
2.4 & $3^{\text {rd }}$ Professional & 63 & 28.1 & \\
2.5 & $4^{\text {th }}$ Professional & 6 & 2.8 & \\
2.6 & $5^{\text {th }}$ Professional & 26 & 11.6 & \\
$\mathbf{2 . 8}$ & Total & $\mathbf{2 2 4}$ & $\mathbf{1 0 0}$ & \\
$\mathbf{3}$ & Type of Institute & & & \\
3.1 & Public Sector & 68 & 28.9 & \\
3.2 & Private Sector & 163 & 69.4 & \\
3.3 & Did not disclose & 4 & 1.7 & \\
$\mathbf{3 . 4}$ & Total & $\mathbf{2 3 5}$ & $\mathbf{1 0 0}$ & \\
\hline
\end{tabular}


Table 3: Self medication information

\begin{tabular}{|c|c|c|c|c|c|}
\hline S.No & Attributes & Sample (N) & Percentage (\%) & Prevalence (\%) & $95 \%$ Confidence Interval \\
\hline 1 & \multicolumn{5}{|c|}{ Indulge in self medication? } \\
\hline 1.1 & Yes & 158 & 67.2 & \multirow{3}{*}{67.2} & \multirow{3}{*}{$60.8 \%-73.2 \%$} \\
\hline 1.2 & No & 77 & 32.8 & & \\
\hline 1.3 & Total & 235 & 100 & & \\
\hline
\end{tabular}

Table 4: Cross tabulation of variables with self medication information

\begin{tabular}{|c|c|c|c|c|}
\hline S.No & Cross-tabulation of Variables & Self Medication & No self medication & $P$ value \\
\hline & & Sample (N) & Sample (N) & \\
\hline 1 & Age & & & $>0.05$ \\
\hline 1.1 & Between $18-23$ years & 148 & 73 & \\
\hline 1.2 & Between $24-30$ years & 9 & 4 & \\
\hline 1.3 & Above 30 years & 1 & 0 & \\
\hline 1.4 & Total & 158 & 77 & \\
\hline 2 & Gender & & & $>0.05$ \\
\hline 2.1 & Male pharmacy students & 25 & 12 & \\
\hline 2.2 & Female pharmacy students & 133 & 65 & \\
\hline 2.3 & Total & 158 & 77 & \\
\hline 3 & Education & & & $>0.05$ \\
\hline 3.1 & Undergraduate & 149 & 75 & \\
\hline 3.2 & Graduate & 8 & 1 & \\
\hline 3.3 & Post Graduate & 1 & 1 & \\
\hline 3.4 & Total & 158 & 77 & \\
\hline 4 & Type of Institute & & & $>0.05$ \\
\hline 4.1 & Public Sector & 47 & 21 & \\
\hline 4.2 & Private Sector & 108 & 55 & \\
\hline 4.3 & Did not disclose & 3 & 1 & \\
\hline 4.4 & Total & 158 & 77 & \\
\hline 5 & Number of Siblings & & & $<0.05$ \\
\hline 5.1 & No siblings & 11 & 14 & \\
\hline 5.2 & Between 1 to 2 siblings & 47 & 21 & \\
\hline 5.3 & Between 3 to 5 siblings & 76 & 32 & \\
\hline 5.4 & Between 6 to 8 siblings & 13 & 6 & \\
\hline 5.5 & More than 8 siblings & 5 & 1 & \\
\hline 5.6 & Did not disclose information & 6 & 3 & \\
\hline 5.7 & Total & 158 & 77 & \\
\hline
\end{tabular}

Table 5: Qualitative beliefs and opinions in favor of self medication

\begin{tabular}{cccc}
\hline S.No & Beliefs and opinions of the pharmacy students presented in favor of self medication & Sample (N) & Percentage (\%) \\
\hline 1 & I have mild problem which can be treated by self medication & 54 & 34.2 \\
2 & Already informed by my prescriber regarding its usage therefore do not feel to consult again / & 17 & 10.8 \\
3 & Previous experience & 12 & 7.5 \\
4 & I find self medication as taking active role in managing my health & 1 & 1.3 \\
5 & Waiting in queues for visiting a doctor is a hassle of time & 1 & 0.6 \\
6 & I do not trust the prescriber's ability to detect my problem & 7 & 0.6 \\
7 & Knowledge about the body is enough to treat one's condition & 64 & 4.5 \\
8 & Informed by elders (non health care professionals) regarding correct use of medications & 158 & 40.5 \\
9 & More than 1 of the aforesaid opinions & Total & 100 \\
\hline
\end{tabular}




\begin{tabular}{|c|c|c|c|}
\hline S.No & Beliefs and opinions of the pharmacy students presented in favor of self medication & Sample (N) & Percentage (\%) \\
\hline 1 & Physician consultation is important to stay healthy & 30 & 39 \\
\hline 2 & Adverse drug reactions $\mathrm{ADR}$ of drugs stops me from taking such risks & 12 & 15.5 \\
\hline 3 & I cannot diagnose my symptoms properly & 7 & 9.2 \\
\hline 4 & I cannot design a rational therapy & 1 & 1.4 \\
\hline 5 & Prescribing has to do with prescribers, not pharmacists & 2 & 2.5 \\
\hline 6 & More than 1 of the aforesaid opinions & 23 & 29.9 \\
\hline 7 & Failed to provide a reason for their decision & 2 & 2.5 \\
\hline 8 & Total & 77 & 100 \\
\hline
\end{tabular}

of the students $(\mathrm{N}=63,28.1 \%)$ were from the $3^{\text {rd }}$ Professional followed by a quarter $(\mathrm{N}=56,25 \%)$ from the $1^{\text {st }}$ Professional year. Slightly greater than a tenth of the target segment belonged to $2^{\text {nd }}$ Professional $(\mathrm{N}=35$, $15.6 \%)$ and $5^{\text {th }}$ Professional year $(\mathrm{N}=26,11.6 \%)$ and some students $(\mathrm{N}=38,16.9 \%)$ chose not to disclose their information on the subject. In addition, more than half of the target segment surveyed $(\mathrm{N}=163,69.4 \%)$ studied in private sector pharmacy teaching institute followed by those $(\mathrm{N}=68,28.9 \%)$ who studied in public sector pharmacy teaching institutes. The summary of educational information is tabulated in Table 2.

\section{Self medication information}

The respondents were asked if they indulge in self medication practices. Majority $(\mathrm{N}=158,67.2 \%)$ responded in favor and a third of the target segment $(\mathrm{N}=77,32.8 \%)$ did not. The prevalence of self medication was found to be $67 \%(60.8 \%-73.2 \%$ for $95 \% \mathrm{CI})$. The self medication information is tabulated in Table 3.

Furthermore, cross tabulation was applied between demographic variables and self medication variable. Significant $P$ values (less than 0.05) obtained for association of siblings with self medication. The cross tabulation is presented in Table 4.

Furthermore, the pharmacy students were asked questions related to their beliefs which rendered their opinions in favor or against indulging in self medication practices. Reasoning affirmative regarding self medication; majority $(\mathrm{N}=54,34.2 \%)$ responded by mentioning that they had mild problems which could easily be treated by self medication followed by those $(\mathrm{N}=17,10.8 \%)$ who were previously informed by the health care professionals regarding correct usage or had previous experience with such treatment, hence they did not feel the need consult the prescriber.

There were some students who found self medication as taking an active role considering one's health $(\mathrm{N}=12,7.5 \%)$. Some of the participants believed it is a hassle to visit a doctor $(\mathrm{N}=2,1.3 \%)$, followed by one student $(\mathrm{N}=1,0.6 \%)$ who had trust issues with the diagnostic ability of prescribers; thus found to advocate for the practice of self medication. There was an opinion by a participant that a knowledge about one's body is enough to treat it as some disease or symptoms appear and supported the self medication $(\mathrm{N}=1,0.6 \%)$. Some $(\mathrm{N}=7,4.5 \%)$ appeared to be informed by elders (non health care professionals) regarding the use of medicine. Other than the aforesaid reasons, a majority of $(\mathrm{N}=64,40.5 \%)$, selected multiple reasons in support of self medication. The qualitative beliefs and opinions of the pharmacy students in favor of self medication are described in Table 5.

Similarly, those responding negatively to self medication had their own beliefs and opinions. Majority $(\mathrm{N}=30,39 \%)$ believed a physicians' consultation is important to stay healthy, followed by those $(\mathrm{N}=12,15.5 \%)$ who were afraid of ADRs. Some of the pharmacy students $(\mathrm{N}=7,9.2 \%)$ believed they cannot diagnose their symptoms properly without a physician's assistance. Some $(\mathrm{N}=1,1.4 \%)$ opined their inability to design a rational therapy. Others $(\mathrm{N}=2,2.5 \%)$ believed prescribing has to do with a prescriber not a pharmacist. Majority of the target segment $(\mathrm{N}=23$, $29.9 \%$ ) chose to support their notion with multiple aforesaid opinions and beliefs. A small number of pharmacy students $(\mathrm{N}=2,2.5 \%)$ did not provide an insight to their decision. The qualitative beliefs and opinions of the pharmacy students against indulging in self medication are described in Table 6.

\section{DISCUSSION}

Self medication is a cause of concern among the undergraduate population of Pakistan. Various studies have been carried out in this regard and reported high prevalence however, none of them investigated the reasons and beliefs of pharmacy students who either indulge or refrain from the practice. The scope of this study was to find out the practice of the pharmacy students without judging it as rationale or irrational. It was aimed at investigating the self medication in the students studying pharmacy degree in both quantitative and qualitative aspects. The main focus was to identify the link up of pharmacy students with self medication practice and investigate the reasons.

The major portion of the age group which is between 18-23 years is arguably very critical and crucial as most decisions by students in this age group are based on inclination which are devoid of any reinforced basis to support. ${ }^{15}$ In terms of gender, majority of the respondents were the females $(\mathrm{N}=198,84.3 \%)$ followed by males $(\mathrm{N}=37,15.7 \%)$. This proportion of pharmacy students in terms of gender represent the current scenario prevailing in the country and such ratio is a hall mark of the medical and pharmacy institutions of Pakistan. ${ }^{16}$

In terms of level of education, an overwhelming majority of the students $(\mathrm{N}=224,95.3 \%)$ were pharmacy undergraduates while some $(\mathrm{N}=9,3.8 \%)$ were graduates followed by very $(\mathrm{N}=2,0.9 \%)$ few post graduates. The charm of being a pharmacy student drives the frame of mind of a student to represent and exhibit the knowledge which distinguishes them from the rest. ${ }^{17}$ The responses from pharmacy students of $1^{\text {st }}$ professional year, $3^{\text {rd }}$ professional year and $5^{\text {th }}$ professional year were crucial as these three stages play important role in designing and reshaping ones professional outlook considering the composition of the coursework in those professional years. ${ }^{18}$ It can be said that in $1^{\text {st }}$ professional year a desire of being known as a student studying in "university", there is a good possibility of noticing the tendency of students to explore the new place, get exposed to unforeseen visage of professional learning environment and learn to orient in the new surroundings. ${ }^{17}$ Thus, in due course, they indulge in making irrational decisions which gradually refines with the time invested in the pharmacy education and acquainting the academia. ${ }^{19}$

It was also reported that more than half of the target segment studied in private sector pharmacy teaching institute followed by almost a third proportion who studied in public sector pharmacy teaching institutes. The issue of self medication is concern for the universities in Pakistan. 
Studies have reported self medication by medical and non medical students in universities of Karachi to $76 \%{ }^{20}$ However it was reported in $40 \%-43 \%$ among non medical students of universities in Islamabad and the authors stated prevalence of self medication to be lower than universities of Karachi. ${ }^{21}$ In the current study the prevalence of self medication among pharmacy students of Karachi was reported at 67.2\% (60.8\%$73.2 \%$ for $95 \% \mathrm{CI}$ ). The results depict a high prevalence of self medication among pharmacy students of universities of Karachi.

Cross tabulating the variable of educational institute and self medication, it was observed that students indulged in self medication were 158 in total $(\mathrm{N}=158)$. A noteworthy number of students $(\mathrm{N}=108 / 158,68.35 \%)$ studied in private sector pharmacy institutions who practiced self medication. However, a significant number was also from public institutions i.e. $(\mathrm{N}=47 / 158,43.5 \%)$. From the results it can be easily calculated that indulging in self medication while studying in private sector pharmacy institution has a ratio of approximately 2:1 against public sector.

It can be said that there are some factors which normally would not be surfaced by students with or without conscience but play a significant role in either encouraging or discouraging the students to indulge in self medication. For instance, the residential area or locality which depicts the trend of its inhabitants regarding self medication and the number of siblings in the family since these two factors have a potential to influence an individual's decision making financially.

On a negative note, this influence can lead to economic reluctance which can prioritize self treatment over prudence since wisdom would deem an expensive consultation necessary but economic reluctance would focus on conservation of resources, hence need to self medicate surfaces. Furthermore, students were also asked to disclose their residential area and number siblings, the bulk of the students $(\mathrm{N}=72,30.6 \%)$ lived in the district Central of Karachi followed by those living in district East $(\mathrm{N}=45,19.2 \%)$ while some students $(\mathrm{N}=39,16.6 \%)$ were living in district South and few in district Malir $(\mathrm{N}=30,12.8 \%)$. A small segment $(\mathrm{N}=9$, $3.8 \%)$ lived in district West and some students $(\mathrm{N}=40,17 \%)$ were reluctant to give this information.

The candidates were asked about the number of siblings in the family, as familial competition is usually regarded as a cause of economic reluctance towards the patients' attitudes concerning the adoption of proper regimental therapy; subsequently replaced by the practices of self medication. To the question of number of siblings, almost half of the target segment $(\mathrm{N}=108,46 \%)$ had 3-5 siblings followed by those $(\mathrm{N}=68$, $28.9 \%)$ who had 1-2 siblings and some ( $\mathrm{N}=19,8.1 \%)$ with 6-8 siblings. Few $(\mathrm{N}=6,2.6 \%)$ had more than 8 siblings and some $(\mathrm{N}=25,10.6 \%)$ had none. However, a small proportion of the target population $(\mathrm{N}=9,3.8 \%)$ did not disclose their information in this regard. Cross tabulating the number of siblings with self medication revealed predictable results. The findings from cross tabulation of two variables debunk those students having 1-2 siblings which accounts for 68 students in total $(\mathrm{N}=68)$, a higher proportion of students $(\mathrm{N}=47 / 68,69.1 \%)$ indulge in practice of self medication while a third ( $\mathrm{N}=21 / 68,30.8 \%)$ do not. Students having 3-5 sibling were 108 in number in this group $(\mathrm{N}=108)$, a significant high number was reported $(\mathrm{N}=76 / 108,70.3 \%)$ which indulged in self medication and less than a third of the target segment $(\mathrm{N}=32 / 108,29.6 \%)$ refrained from self medication. This trend was repeated in other groups as students having 6-8 siblings, were 19 in total out of which majority $(\mathrm{N}=13 / 19,68.4 \%)$ while few $(\mathrm{N}=6 / 19,31.5 \%)$ abstained from the practice. Although students with more than 8 siblings were less in number $(\mathrm{N}=6)$ but an overwhelming majority $(\mathrm{N}=5 / 6,83.3 \%)$ was found indulged in due course and only a single student did not $(\mathrm{N}=1 / 6,16.6 \%)$. Those students with no siblings were reported to be 25 in number out of which more than half of the segment $(\mathrm{N}=14,56 \%)$ did not indulge in self medication and less than half however did $(\mathrm{N}=11,44 \%)$. The findings were statistically significant (P-value $<0.05)$.
It was quite evident that the increasing number of siblings was a major factor for indulgence in self medication. Moreover the trend towards indulging in self medication was low in students with no siblings as majority of the students did not practice self medication. As the number of siblings increased the equation shifted in favor of indulging in self medication. The results strengthen the hypothesis that familial competition leads to economic reluctance and have a lot more impact on decision making in favor of self medication. Students who are a part of larger families do not rely on the regular costly consultations or purchase drugs after the authorization of a prescriber. Despite being a pharmacy student, for them it seems to be little too heavy on pocket to consult a prescriber which incite the tendency to indulge in self medication. This phenomenon of indulging in self medication despite knowledge was also reported in the study carried out by Zafar SN et al 2008 which found out no significant difference in self medication practice of medical and non medical students. ${ }^{1}$ Hence, the same can be applied to pharmacy students. On the other hand people having no siblings depicts a totally opposite picture with majority not practicing self medication which reconfirms the hypothesis from other end.

Question related to indulging in self medication practices was asked from the students of pharmacy who hold the information or the core knowledge about the drugs and their pharmacology..$^{10}$ The study reported more the half $(\mathrm{N}=158,67.2 \%)$ of the total sample pool engaged into the self medication practices while a third $(\mathrm{N}=77,32.8 \%)$ refrained from such practice. The females were reported to be more in number and indulged in self medication for most part ( $\mathrm{N}=133 / 158,84.1 \%)$. Cultural values are indicative that females usually are not advised or practiced to be taken to a physician unless serious concerns regarding health arise. ${ }^{22}$ In general females are deemed by the society to stay home. ${ }^{8}$ This stance on females is also evidenced from the data gathered as the target population majorly comprised of females and out of the total sample indulged in self medication an overwhelming majority were the females.

On the qualitative aspect, those in favor of self medication were further inquired about their reasons, beliefs and opinion which ultimately led to their decision. Some students $(\mathrm{N}=54,34.2 \%)$ reasoned having mild problems which could easily be treated by self medication hence they felt it is normal. This reason was also reported by a number of studies conducted in medical and non medical universities in Karachi, Pakistan though the percentages reported were less $(46.9 \%)^{1}$ and $(48.3 \%) .{ }^{20}$ Nevertheless the current study hypothesized the reason of 'mild problems' as a major contributor in indulgence in self medication by any student whether that be medical, non medical or pharmacy. A number of students told they had previously been informed by the health care professionals regarding correct usage or had previous experience with the medication hence they did not feel the need consult the prescriber again. This reason was also reported among medical and non medical students of different universities in Karachi, Pakistan by Zafar SN et al 2008. ${ }^{1}$ However, the study reported about $50.1 \%$ of students having such reason. Another study by Mumtaz Y et al 2011 reported figures 30.9\%. ${ }^{20}$ A study by Hussain A. and Khannum A. 2008 also reported a percentage of $23.8 \%$ in favor of self medication based on this reason. ${ }^{21}$ In the current study, the figures were reported to be less than all previous studies conducted i.e. $(\mathrm{N}=17$, $10.8 \%)$.

There were some students who found self medication as taking an active role considering one's health $(\mathrm{N}=12,7.5 \%)$. In an article by Suryawati S. 2003, she highlighted the improvement in quality of self medication through active learning of parents. She opines self medication is beneficial for minor ailments if the patient has an active approach towards learning of medicines. ${ }^{23}$ It is possible that her opinions are being second by the students of this group. However, the scope of minor ailments remains unclear and needs to be further investigated. Some of the participants found visiting a doctor a hassle for their time in terms of long waiting 
queues $(\mathrm{N}=2,1.3 \%)$. This reason is also reported by non medical students however the percentages were quite high. ${ }^{20}$ The reason of low percentages in pharmacy students as compared to non medical ones can be either linked to education in allied health background or understanding of importance of physician's consultation.

Some of the students $(\mathrm{N}=1,0.6 \%)$ had trust issues with the diagnostic ability of prescribers; thus found to advocate for the practice of self medication. In an article by Luisa Dillner 2014, she highlighted the importance of trusting one's doctor. According to her, people who do not trust their doctor / prescribers will be more distressed, physically disabled and less likely to take care of themselves. ${ }^{24}$ Hence, this mistrust will only lead to adverse outcomes. There was an opinion by a participant that a knowledge about one's body is enough to treat the condition $(\mathrm{N}=1$, $0.6 \%$ ). This was quite amazing as it was evident in a study conducted on the self medication and patient knowledge which, although reported encouraging results but also mentioned that even after self medication, $45 \%$ of the patients had knowledge regarding medications on level one which accounts for basic knowledge. ${ }^{25}$ Hence, a claim by student having adequate knowledge to indulge in self medication can be a mere rhetoric. Similarly, those responding negatively to self medication had their own beliefs and opinions. Majority $(\mathrm{N}=30,39 \%)$ believed a physicians' consultation is important to stay healthy. Some of the pharmacy students $(\mathrm{N}=7,9.2 \%)$ believed they cannot diagnose their symptoms properly without a physician's assistance and some students $(\mathrm{N}=12,15.5 \%)$ feared the ADRs of the drugs. Some other opinions that were surfaced in the interviews were the inability of pharmacy students to design a rational therapy $(\mathrm{N}=1,1.4 \%)$. In this context, a number of studies emphasize the importance of doctor-patient communication in improving the quality of health of the patients. ${ }^{26}$ Hence, wisdom demands to consult a doctor/ prescriber for ailments instead of self medication. There was an opinion that prescribing has to do with a doctor/prescriber not a pharmacist hence as a pharmacy student one should refrain from self prescribing $(\mathrm{N}=2,2.5 \%)$. In this context, developed countries such as the UK, US, Canada and Australia have practitioners having the right and responsibility to prescribe with some provision of pharmacists and nurses eligible for diagnosis and prescribing. ${ }^{27-29}$ However, the very opinion of the pharmacy students is reasonable in local and regional context as the doctors are deemed to be ones having sole right to prescribe in Pakistan. ${ }^{30}$ Furthermore, some pharmacy students $(\mathrm{N}=2,2.5 \%)$ did not provide an insight to their decision. This might be due to the irrational judgments highlighted earlier that most decisions by students in this age group are based on likeness and inclination towards self medication which are devoid of any reinforced basis to support. ${ }^{15}$

\section{CONCLUSION}

The practice of self medication is considered as an investment as the socioeconomic hindrance cause students to be reluctant to spend money on consultation hence the pharmacy graduates would follow the same trend and practices prevailing in the society. In fact they find themselves more poised and authoritative in indulging in such practices. The economic barriers and familial competition, dysregulated pharmaceutical drug selling, limited prescribers and absence of pharmacists in pharmaceutical retailing are the core factors which facilitates self medication.

\section{Strengths and limitation of study}

The study employed validated questionnaire with aide of research assistant to facilitate swift quantitative data gathering. Triangulation was applied to the qualitative arm of the study and the findings adhered to COREQ guidelines. The study employed convenience sampling to gather responses in close proximity hence inferior to probability sampling in it representativeness. The sample size was not fairly large hence the results cannot be generalized.

\section{ACKNOWLEDGEMENTS}

The authors extend their gratitude to Dr Muntazir Zaidi and staff of Clifton Hospital, Karachi, Pakistan for their support in validation of questionnaire and would also like to thank all the volunteers for assisting data acquisition and the respondents for giving their honest opinions.

\section{SUPPORTING INFORMATION}

This research was also presented in $4^{\text {th }}$ International Conference on Endorsing Health Science Research (ICEHSR) Health Care: Mission to Vision organized by Advance Educational Institute and Research Centre AEIRC, held on April 9 $9^{\text {th }} 2016$ in Karachi, Pakistan.

\section{CONFLICT OF INTEREST AND FUNDING INFORMATION}

The authors declare they have no conflict of interests. No funding was sought for the study.

\section{CONTRIBUTION OF THE AUTHORS}

$\mathrm{AA}, \mathrm{RA}$ and MHK conceived the idea, wrote the introduction and designed the questionnaire with $\mathrm{OQ}, \mathrm{MN}$ and MA. AA formulated the research design and wrote methods. Data was collected and tabulated by $\mathrm{MN}$ and MA. Furthermore, data analysis was done by AA, MN, MA and results were written by AA, MHK and OQ. The discussion and conclusion were written by AA, RA and OQ. Final drafting of the manuscript and abstract written was done by AA. All authors read and approved the final manuscript. (AA=Atta Abbas Naqvi, RA=Rizwan Ahmad, OQ=Omar Qadeer, MHK=Muhammad Hassan Khan, MN=Muhammad Nehal, MA=Madiha Alim).

\section{ABBREVIATIONS USED}

OTC: Over the counter; ADR: Adverse drug reactions; UK: United Kingdom; US: United States. 


\section{REFERENCES}

1. Syed NZ, Reema S, Sana W, Akbar JZ, Talha V, Mehrine SWY. Self-medication amongst University Students of Karachi: Prevalence, Knowledge and Attitudes. Journal of the Pakistan Medical Association. 2008;58(4):214-7.

2. Yasmin M, Ashraf JSM, Tahira M, Shahla Z, Sara A. Self Medication among University Students of Karachi. Journal of Liaquat University of Medical and Health Sciences. 2011;10(3):102-5.

3. Chowdhury N, Matin F, Chowdhury SF. Medication taking behavior of students attending a private university in Bangladesh. Int J Adolesc Med Health. 2009;21(3):361-70.

4. Atta AN, Ken M. Polypharmacy in Pakistan. Saarbrucken, Germany: Lap Lambert Academic Publishing Corp. 2014.978-3-659-56506-9.

5. Atta A, Nabeel K. Clinical Trials Involving Pharmacists in Pakistan's Healthcare System: A Leap from Paper to Practice. Pharmacy. 2014;2(3):244-7.

6. Atta A, Farrukh RA, Mehwish R, Muhammad HK, Bharti K. Evaluation of drug dispensing practices by pharmaceutical drug retailers in Pakistan. World Journal of Pharmaceutical Research. 2015;4(2):189-97.

7. Asa A Simeon O, Temitope JF Shalkur D, Samuel BB. Medicine Vendors: Selfmedication Practices and Medicine Knowledge. North American Journal of Medical Sciences. 2012;4(1):24-8.

8. Van Duong D, Binns CW, Van Le T. Availability of antibiotics as over-the-counter drugs in pharmacies: a threat to public health in Vietnam. Trop Med Int Health. 1997;2(12):1133-9.

9. Morgan DJ, Okeke IN, Laxminarayan R, Perencevich EN, Weisenberg S. Nonprescription antimicrobial use worldwide: a systematic review. The Lancet Infectious Diseases. 2011;11(9):692-701.

10. Osemene KP, Lamikanra A. A Study of the Prevalence of Self-Medication Practice Among University Students in Southwestern Nigeria. Tropical Journal of Pharmaceutical Research. Tropical Journal of Pharmaceutical Research. 2012;11(4):683-9.

11. Auta A, Banwat SB, Sariem CN, Shalkur D, Nasara B, Atuluku MO. Medicines in Pharmacy Students' Residence and Self-medication Practices. Journal of Young Pharmacists. 2012;4:119-23.

12. Azhar $\mathrm{H}$, Asifa Khannum. Self-medication among university students of Islamabad, Pakistan-a preliminary study. Southern Med Review. 2008;1(1):14-6.

13. Atta A, Farrukh RA, Raafia Y, Nabeel K, Zeb-un-Nisa, Syed IA, et al. The prevalence of psychoactive stimulants and antidepressants among undergraduate pharmacy students in twelve Pakistani cities. Tropical Journal of Pharmaceutical Research. 2015;14(3):527-32.

14. Wikipedia. [Homepage on internet]. Karachi. [updated 2015; cited $20^{\text {th }}$ Nov 2015]. Available: http://en.wikipedia.org/wiki/Karachi.

15. De Moraes ACF, Delaporte TRM, Molena-Fernandes CA, Falcão MC. Factors associated with medicine use and self medication are different in adolescents. Clinics. 2011:66(7):1149-55.

16. Rafia Z. Dawn News. [Homepage on internet]. The Doctor Brides. [updated January 31, 2013; cited March 1, 2014.]. Available from:. http://www.dawn.com/ news/1032070/the-doctorbrides.

17. Muhammad N, Atta A. The rants of an undergraduate pharmacy student A reflection. Medical Science. 2014;11(44):84-5.

18. Higher Education Commission of Pakistan (HEC). [Homepage on internet] Curriculum of Doctor of Pharmacy. [updated 2011; cited November 1, 2015]. Available from: https://pharmareview.files.wordpress.com/2013/03/pharmacycurriculum-2011-revised.pdf.

19. Atta A, Syed AR, Rabiya H, Nasar A, Marium K, Anum B, et al. The prevalence of depression and its perceptions among undergraduate pharmacy students. Pharmacy Education. 2015;15(1):57-63.

20. Yasmin M, Ashraf JSM, Tahira M, Shahla Z, Sara A. Self Medication among University Students of Karachi. JLUMHS. 2011;10(3):102-5.

21. Hussain A, Khanum A. Self medication among university students of Islamabad, Pakistan-a preliminary study. Southern Med Review. 2008;1(1):14-6.

22. Olga Khazan. The Atlantic. [Homepage on internet]. All the Reasons Women Don't Go to the Doctor, Other Than Money. [updated May 15, 2014; cited: November 28, 2015.] Available from: http://www.theatlantic.com/health/archive/ 2014/05/all-the-reasons-women-dont-go-to-the-doctor-other-than-money/ 370952/.

23. Suryawati S. CBIA: improving the quality of self-medication through mothers' active learning. [Homepage on internet]. [updated 2003; cited Novermber 30, 2015] Available: from: http://www.asksource.info/resources/cbia-improving-qualityself-medication-through-mothers-active-learning.

24. Luisa Dillner. The Guardian. [Homepage on internet]. How important is it to trust my doctor? [updated 2014; cited November 30, 2015]. Available from: http:// www.theguardian.com/lifeandstyle/2014/jul/27/how-important-is-it-to-trust-mydoctor.

25. Grantham G, McMillan V, Dunn SV, Gassner LA, Woodcock P. Patient self-medication--a change in hospital practice. J Clin Nurs. 2006;15(8):962-70.

26. Jennifer FH, Nancy L. Doctor-Patient Communication: A Review. Ochsner J. 2010 Spring; 10(1):38-43.

27. General Practitioner Committee. GPC. [Homepage on internet]. Prescribing in general practice. [cited November 30, 2015]. Available from: http://bma.org.uk/ practical-support-at-work/gp-practices/service-provision/prescribing.

28. American Pharmacist Association. APhA. [Homepage on internet]. A tale of two countries: The path to pharmacist prescribing in the United Kingdom and Canada. 2014. [cited $2^{\text {nd }}$ December, 2016]. Available from: http://www.pharmacist.com/tale-two-countries-path-pharmacist-prescribing-united-kingdom-andcanada.

29. The Pharmacy Guild of Australia. [Homepage on internet]. [cited $2^{\text {nd }}$ December 2015]. Available from: http://www.guild.org.au/docs/default-source/public-documents/tab---the-guild/Strategic-Direction/pharmacist-prescribing.pdf?sfvrsn=0.

30. Pakistan Medical and Dental Council. PM\&DC. [Homepage on internet]. [cited $2^{\text {nd }}$ December, 2015]. Available from: http://www.pmdc.org.pk/AboutUs/tabid/72/Default.aspx. 